\title{
Fuzzy Logic Based Life Cycle Cost Analysis Model for Preventive Road Maintenance by Considering User Costs
}

\author{
Dadang Iskandar', Sigit Pranowo Hadiwardoyo², R. Jachrizal Sumabrata ${ }^{3}$ \\ ${ }^{1}$ Ph.D., Student, Civil Engineering Department, Faculty of Engineering Universitas Indonesia, Indonesia. \\ ${ }^{2}$ Professor, Civil Engineering Department, Faculty of Engineering Universitas Indonesia, Indonesia. \\ ${ }^{3}$ Associated Professor, Civil Engineering Department, Faculty of Engineering Universitas Indonesia, Indonesia.
}

${ }^{1}$ ORCID: 0000-0001-5263-7706

\begin{abstract}
Road maintenance programs are an important requirement so that road performance remains stable. Life cycle cost analysis (LCCA) is one of the methods in the pavement management process. LCCA is used to support decision makers as a network level analysis tool. Many transportation agencies have used deterministic and probabilistic LCCA approaches. Decision makers use the probability method to evaluate investment risk using input variables, assumptions, or uncertain estimates. Data input is ambiguous and uncertain, so the use of soft computing applications can be used. This paper discusses the development of LCCA preventive maintenance tools for road pavement using soft computing techniques. Fuzzy logic-based algorithm presents LCCA for pavement preventive maintenance by considering user costs. Algorithm with a rule-based fuzzy logic system where users can define rules to reflect agency policies and strategies. This algorithm is part of a framework that can be proposed for the use of other soft computing techniques in handling preventive maintenance of roads
\end{abstract}

Keywords: User Costs, Preventive Road Maintenance, Fuzzy Logic, Life Cycle Cost Analysis

\section{INTRODUCTION}

Various problems regarding road maintenance generally increase road pavement damage, traffic volume and burden, and increasingly limited natural resources. Another problem is the financial constraints that make the task of maintaining pavement networks more difficult compared to the previous conditions. Road conditions will gradually decline due to environmental use and influence. In some cases, road performance did not meet design expectations, resulting in a decrease in the level of service that road users could utilize. In Indonesia this decline has been clearly informed in a recent survey conducted by the Ministry of Public Works in 2018 [1]. According to this survey, ten percent of roads in Indonesia are in an unstable condition, and these conditions contribute to an increase in road fatalities accidents [2].

The level of damage to pavement depends on the amount of traffic, environmental conditions, material quality, and maintenance policies. Road damage can be divided into three categories, namely surface damage in the form of cracking, raveling and potholing; deformation damage in the form of rutting and roughness and surface texture damage in the form of texture depth and skid resistance [3]. Efforts to prevent damage so that it does not get worse before the end of service life, a preventive pavement maintenance program is an option in the road maintenance program. Several studies have proven the benefits of the PPM strategy, which is the cost of four times the PPM is still smaller than twice the large maintenance and even reconstruction. The PPM strategy has produced a damage index of only half the maintenance costs in 20 years during the analysis period. Therefore, in terms of both costs and benefits, the use of the LCCA method by choosing a PPM strategy has resulted in optimization benefits for long-term pavement performance [4]. The actions of the agency by ignoring road damage that are not immediately repaired have little effect on agency costs. Immediate repairs, or repairs postponed a week, a month or even a year only slightly add to the costs significantly. The opposite condition occurs for road users because road damage results in increased travel time, additional vehicle maintenance costs and lost opportunities due to delays to their destination [5]. LCCA is an economic analysis tool used to support pavement maintenance and asset management decisions. The LCCA process consists of several assessments, predictions, and assumptions. Precise pavement performance estimates, traffic for some time and future cost analysis determine the reliability of LCCA results. LCCA implementation sometimes has difficulty in measuring nonagency costs such as user cost, most LCCA only uses late fees as part of user cost [6]. This technique relies on estimates of future pavement performance, maintenance and rehabilitation care, and user costs. Road performance estimates are often based on information uncertainty, ambiguity, subjective, and sometimes incomplete, soft computing techniques have emerged as a very attractive alternative for developing LCCA tools. Soft computing includes computational techniques that tolerate inaccuracies, uncertainties, and ambiguity. Specifically, fuzzy logic systems provide a formal approach to solving this type of information.

This paper evaluates the feasibility of developing LCCA computational preventive software maintenance by considering user costs. This paper also provides a brief review of the concept of fuzzy logic systems and proposes a general framework for use with other soft computing techniques in the development of efficient tools for economic analysis of road maintenance activities, especially road Maintenance and Rehabilitation (MR). 


\section{RELATED STUDY}

Several previous studies have developed the concept of softcomputing by presenting a fuzzy mathematical analysis approach in developing strategic planning for the maintenance and rehabilitation of pavement [7]. Fuzzy Analytical Hierarchy Process (FAHP) techniques have produced a basic model scientific approach to assess road conditions. An artificial bee colony algorithm is proposed to solve the problem of optimizing the surface of the road pavement. This algorithm resembles the collective behaviour of bees when searching for nectar. In this approach, various scenarios are generated, the optimality of each case is evaluated, and the information generated is used in subsequent evaluations to achieve global optimality. The application of soft computing has been carried out in the management of urban pavement maintenance. Three soft computing which are widely used are artificial neural networks, fuzzy systems and genetic algorithms. Synergistic integration is needed to become a hybrid model $[8,9]$.

There are several soft computing techniques, such as artificial neural networks, fuzzy systems, and genetic algorithms, which have been used in infrastructure management with varying degrees of success. Soft computing techniques have proven effective for pavement management and infrastructure applications. This technique allows the completion and processing of subjective and ambiguous information, as well as incomplete data sets [10].

\section{UTILIZATION OF SOFT COMPUTING FOR ENGINEERING ANALYSIS}

Soft computing includes three main constituents: neural networks, fuzzy programming, and genetic algorithm computing [11]. The reason for choosing soft computing in the development of engineering economic analysis tools is that the information available for various pavement projects is highly variable, uncertain, ambiguous, and incomplete. Numerical and linguistic data can be available and must be considered in the analysis. In addition, some relevant factors are easily measured in economic or technical terms. Factors such as environmental impact, comfort, aesthetics, flexibility, and mobility considerations are part of the user's cost, better evaluated using subjective terms.

\section{PREVENTIVE PAVEMENT MAINTENANCE}

The process of condition assessment and pavement performance prediction are the two keys to a successful infrastructure management system. Most infrastructure management systems include modules that analyze the condition of assets by creating an index that reflects the overall condition of the structure. How to predict the condition of future assets based on present conditions needs to be used for all levels of decision making. The research conducted by Terzi et al included three input parameters SUM ESAL, SN, and AGE combined to simulate IRI using ANFIS data. This model of pavement performance can be estimated and can predict future performance conditions so that maintenance scheduling can be done at the same time to prepare the budget [12].

\section{USER COST}

Additional User Cost is defined as an estimated daily additional cost for people traveling as a result of obstacles or delays in the road due to construction work or due to road damage. These costs are due to the regulation of traffic flow and the detour that results in increased travel time, reduced road capacity which results in a decrease in speed [13]. The results of previous studies indicate that the addition of agency costs is very small compared to the costs of road users. The addition of costs is only less than $4 \%$ of the total costs and investment of the agency in increasing rehabilitation activities [14].

The impact of a decrease in speed caused by damage to roads or obstacles will lead to an increase in road user costs as a result of increased vehicle operating costs and increased opportunity costs due to time delays at the destination. It is expected that the application of this research will reduce user costs incurred by road users, so that road maintenance programs are more useful.

\section{METHOD}

\section{VI.I. Fuzzy Logic Systems}

Fuzzy system design requires the definition of a set of membership functions that allows the system to handle uncertainty, and various rules. Relationships can be achieved by using descriptive expressions, such as poor, fair, or good (Figure 1), to categorize linguistic input and output variables. Fuzzy logic was developed to provide soft algorithms for data processing that can make conclusions about inappropriate data and how to use data. This allows the variable to partially belong to a particular set, and at the same time, it uses the generalization of conventional Boolean logic operators in data processing.

Fuzzy logic systems use fuzzy sets, having a degree of membership in the range of zero to one. Fuzzy logic is used to translate a quantity that is expressed using linguistics. For example, the magnitude of the speed of the vehicle that is expressed very slowly, slow, fast and very fast

In this paper there are 3 input variables consisting of the Present Serviceability Index (PSI), Speed and Time. PSI describes the road surface performance index with a descriptive expression, very poor for road surface conditions with the lowest index and excellent for road surface conditions with the highest index, the input speed and time parameters are used to include their effects on user costs.

\section{VI.II. Consideration of Use Cost based on Speed Change}

The process of speed changes directly affects the amount of user cost. The user cost component consists of Vehicle Operating Costs (VOC), Accident Costs (AC), time value costs (VOT) and toll costs [15]. For the calculation of AC and VOT in this paper are not discussed in detail, only calculated generally based on the GRDP [16].

This study has tested several fuzzy-based models using the help of MATLAB R2016b software. The model has tested the trigger and policy model as follows: 1) Do Nothing as a trigger 
model; 2) Preventive Maintenance; 3) Overlay; and 4) Reconstruction.

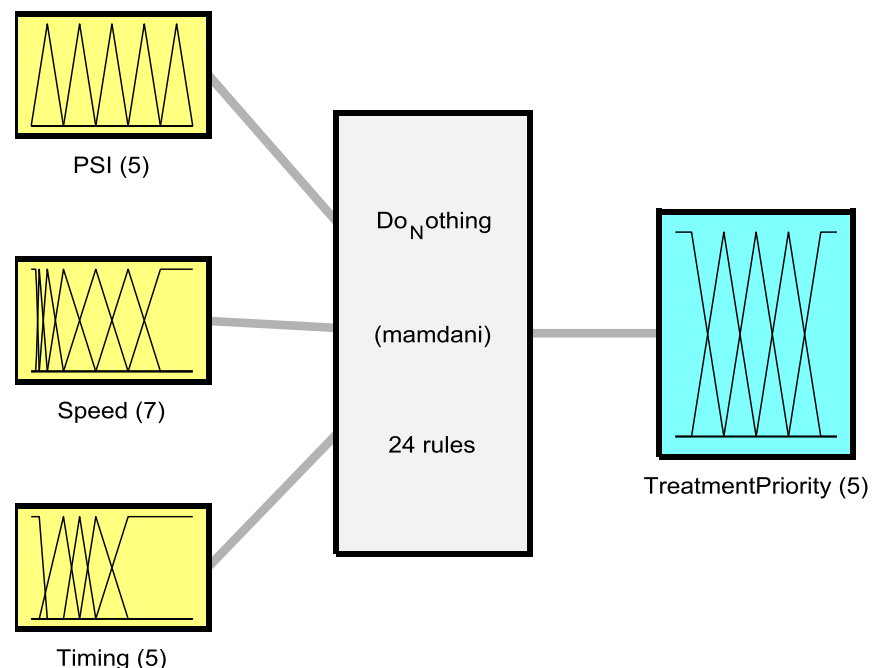

Figure 1. Fuzzy interfered system for trigger model 1 (Do Nothing)

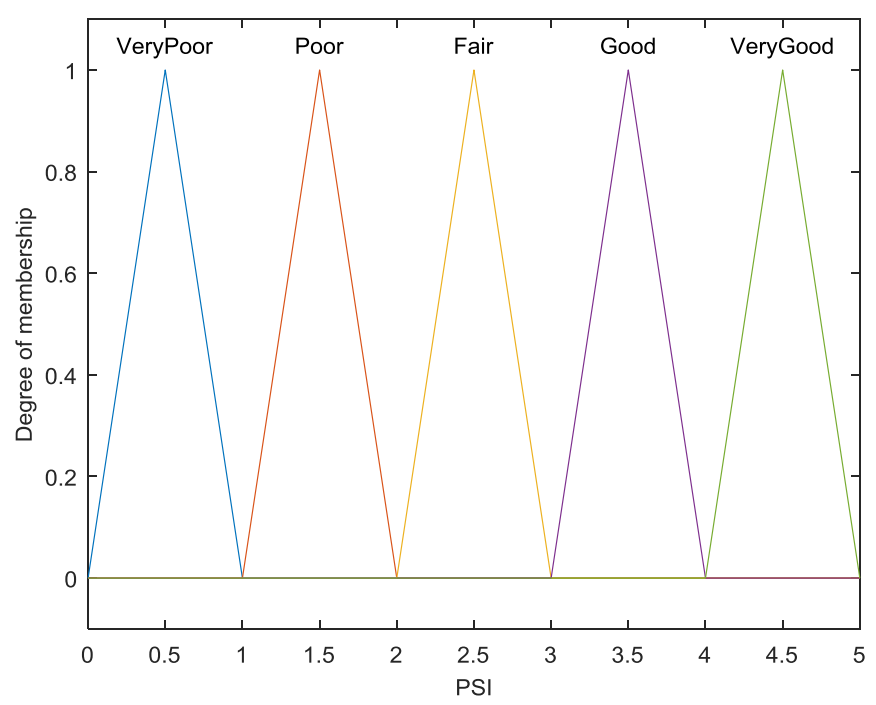

Figure 2. Membership function for input 1 (PSI)

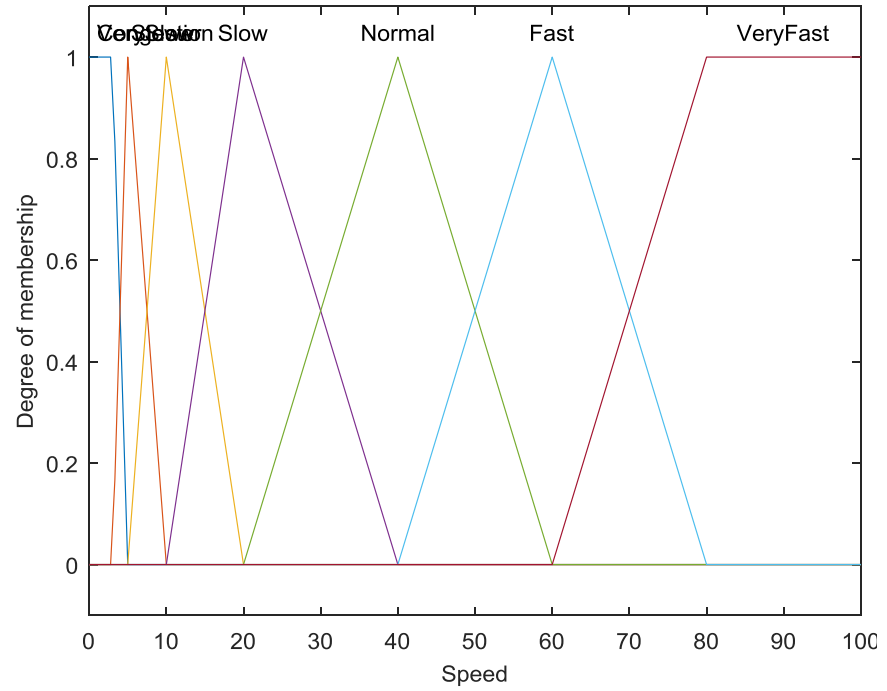

Figure 3. Membership function for input 2 (speed)

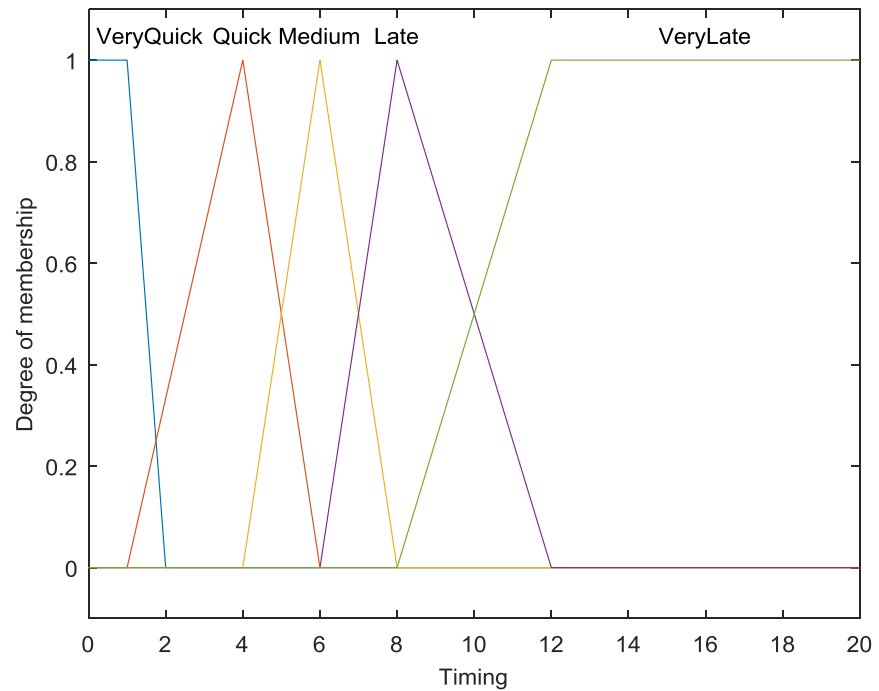

Figure 4. Membership function for input 3 (timing)

In Figure 1. shows the fuzzy system design for the Do Nothing trigger model with a set of system membership functions that handle uncertainty with a set of rules using the descriptive expression Poor, Fair, and Good.

Figure 2 describes the PSI input variables that have a membership in accordance with the limits of the index set by HCM 2010 [17], with the category of very poor, poor, fair, good and very good. For the input speed variable, membership that is applied congestion, is very slow, slow, normal, fast and very fast as described in Figure 3

Whereas the determination of the treatment time for the membership category applied starts from very quick, quick, medium, late to very late according to Figure 4.

The resulting output is the priority treatment that will be applied according to the model tested with membership as illustrated in figure 5 .

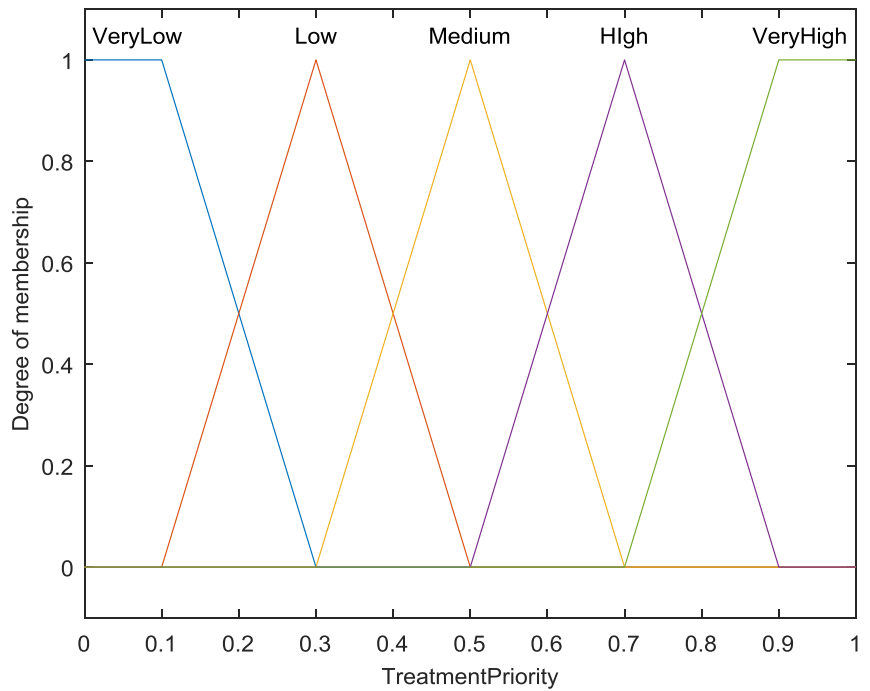

Figure 5. Membership function for output (treatment priority) 
The rule-based fuzzy logic system is composed of four parts: the rule base, the input processor (fuzzifier), the inference engine, and the output process [18]. Rules can be provided by experts, based on case examples, or a combination of the two.

Then the models are tested for various treatments, various models are tested, namely:

1. Do Nothing as a trigger model,

2. Preventive Maintenance (PPM) as a policy model,

3. Overlay $(5 \mathrm{~cm})$ as the policy model, and

4. Reconstruction as a policy model.

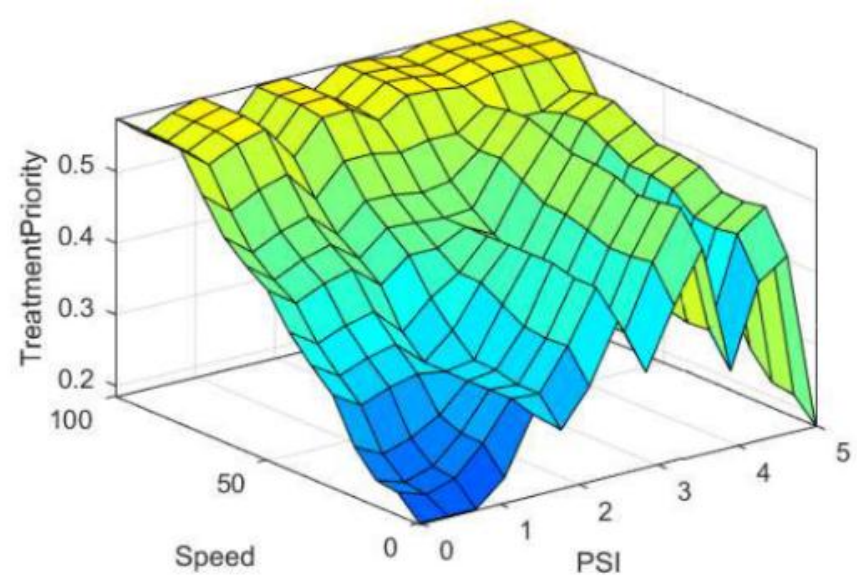

Figure 6. Surface plot PSI and speed for model Do Nothing test

The process of testing the model for Do Nothing as described in figure 6 and figure 7 . Whereas the test for the Preventive Maintenance model is described in figure 8 and figure 9.

The rules in fuzzy logic systems are often stated in the form of IF-THEN statements. The input and output process provides quantitative and linguistic data. The inference engine handles the application of related rules.

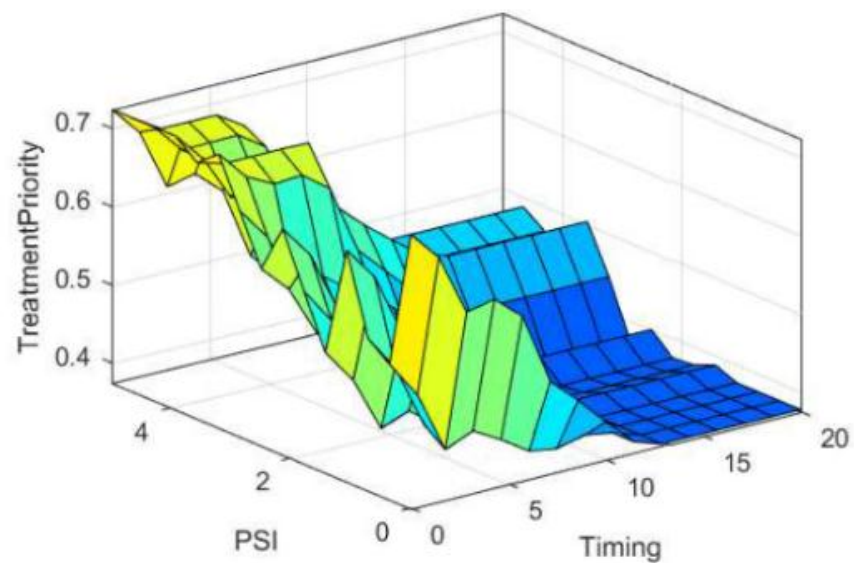

Figure 7. Surface plot Timing and PSI for model Do Nothing test

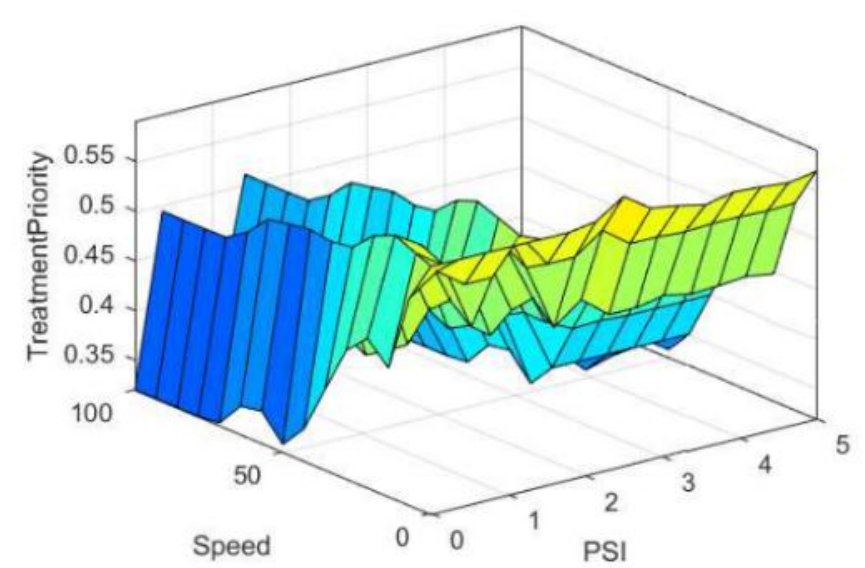

Figure 8. Surface plot PSI and speed for model PPM test

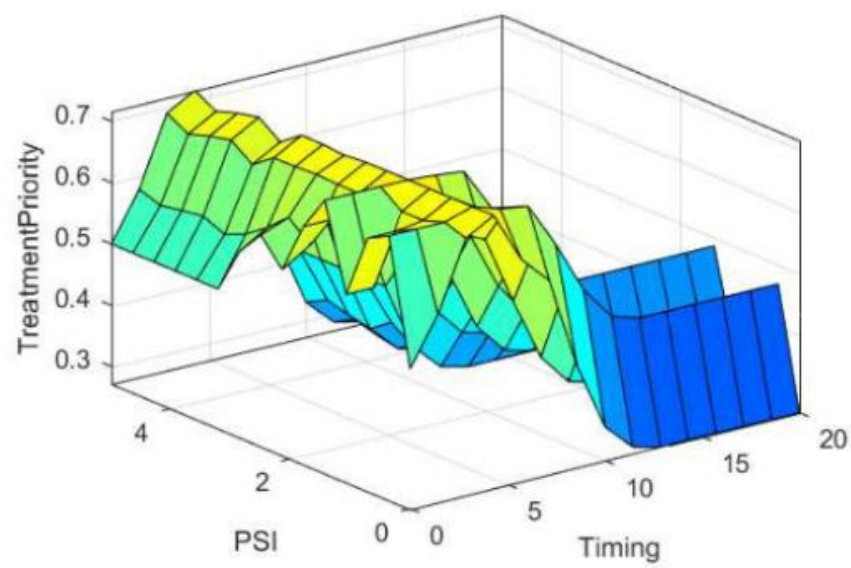

Figure 9. Surface plot timing and PSI for model PPM test

\section{FUZZY LOGIC-BASED LCCA}

\section{VII.I. Agency Costs Model}

The main part of the LCCA is determining agency costs including construction, maintenance and rehabilitation costs for the pavement during the analysis period. Initial construction costs can generally be obtained from construction costs and a pavement management system. Expenditures for future maintenance are unknown at the time of LCCA and can only be estimated based on agency policies or maintenance costs from similar projects.

There is often uncertainty about agency costs from unknown pavement performance, future maintenance and rehabilitation and reconstruction actions. The initial step to demonstrate the feasibility of the approach, the fuzzy system is used for project selection or can be made by pavement performance reduction models.

\section{VII.II. Considering User Cost}

The calculation of the user's cost includes vehicle operating costs, travel time, accident costs and environmental impact. Estimated vehicle operating costs require information about traffic conditions, pavement, fuel, vehicle repair, and others. The calculation of vehicle operating costs uses Indonesian standards [19]. 
Accident cost analysis requires estimation of accident rate data from accident frequency data. Estimates are based on geometric characteristics of roads, pavement conditions, and traffic distribution. The costs of environmental impacts as well as noise and other factors are not easy to estimate because of uncertainty in information, ambiguous and or incomplete. Accident costs and environmental impacts in this study have not been considered as input variables due to data limitations.

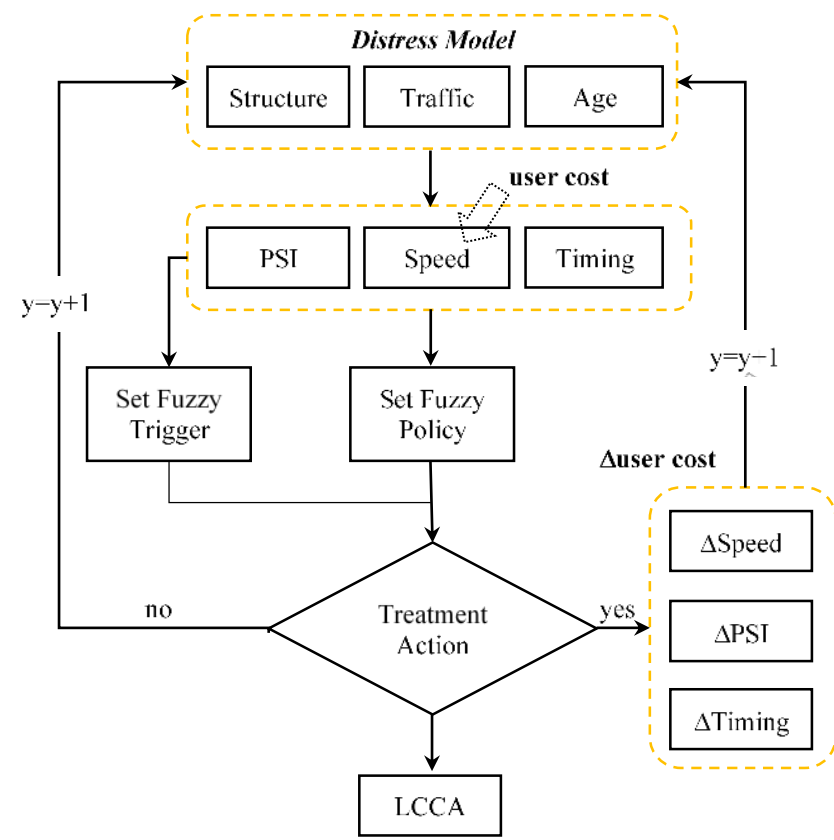

Figure 10. Fuzzy logic-based project selection algorithm considering user cost

Figure 10 illustrates the algorithm used in this paper. The algorithm consists of two rules based fuzzy logic models, the trigger model and the policy model. The trigger model calculates the priority of treatment doing nothing, while the policy model is used to evaluate the priority of preventive, overlay and reconstruction maintenance.

\section{CASE STUDY}

The field data collection process in this study was carried out on the Jakarta Outer Ring Road Section S (JORR-S) by conducting a survey of vehicle speed changes using the Metro-
Count ROADPOD VT5900. The placement of the recording device is arranged with the following scenario:

1. Data collection is carried out during normal working days for more than 24 hours, compared to recording data on weekdays during window time. The recording results are presented in figure 11 and figure 12 .

2. Data collection is done during normal conditions on weekends for more than 24 hours then compared with data on weekends during window time. The recording results are presented in figure 13 and figure 14.

Regulations to maintain comfort and safety during the construction work period are based on regulations stipulated by the Toll Road Management Agency, the time of construction work for JORR-S is only carried out only at window time, from $22.00 \mathrm{pm}$ to $05.00 \mathrm{am}$.

In normal traffic conditions during weekdays the vehicle traffic volume can be seen to be relatively high, namely during rush hour with a decrease in speed resulting in vehicle queues, and when road improvements are made when the vehicle window time volume is relatively low and vehicle queues continue to occur resulting in congestion. From the survey conducted at the weekend, the volume of vehicle traffic is relatively lower, but when repairing the road by closing 2 lanes of the road, there have been vehicle barriers resulting in queues.

The process of calculating user costs is based on benefit cost, which is the difference between the costs of vehicle users under normal conditions and the cost of road users on the condition of obstacles caused by damage or road repairs.

Some examples of user cost calculations according to Indonesian standards in JORR-S are shown in table 1.

To calculate the benefit user costs due to lane closure per day using the following equation:

$$
\sum U C_{\text {day }}=A A D T \times \overline{\Delta U C}
$$

With $\mathrm{AADT}=23,500$, for a lane closure or a lane is blocked due to damage or repairs, it will cause a decrease in speed. The total difference of $\mathrm{UC}\left(\sum U C_{\text {day }}\right)$ is billion IDR 0.029. This condition should not occur for a long time and it can cause additional travel costs for users. The loss of road user costs on high traffic roads will increase to billion IDR 10.406 for the one year delay of road repair (table 2).

Table 1. Calculation of user cost benefits in JORR-S

\begin{tabular}{|c|c|c|c|c|c|c|c|c|c|}
\hline \multirow[b]{2}{*}{ Time Span } & \multicolumn{4}{|c|}{ Normal Lane with IRI $\leq 2$} & \multicolumn{4}{|c|}{ Lane Closure with IRI $\geq 4$} & \multirow{2}{*}{$\begin{array}{l}\Delta \mathrm{UC} \\
\text { (IDR) }\end{array}$} \\
\hline & $\begin{array}{l}\text { Speed } \\
(\mathrm{km} / \mathrm{h})\end{array}$ & $\begin{array}{c}\text { VOC } \\
\text { (IDR) }\end{array}$ & $\begin{array}{c}\text { VTT } \\
\text { (IDR) }\end{array}$ & $\begin{array}{c}\mathrm{UC} \\
\text { (IDR) }\end{array}$ & $\begin{array}{l}\text { Speed } \\
(\mathrm{km} / \mathrm{h})\end{array}$ & $\begin{array}{c}\text { VOC } \\
\text { (IDR) }\end{array}$ & $\begin{array}{l}\text { VTT } \\
\text { (IDR) }\end{array}$ & $\begin{array}{c}\mathrm{UC} \\
\text { (IDR) }\end{array}$ & \\
\hline $22.00-23.00$ & 70.8 & 1232.12 & 146.21 & $1,378.33$ & 11.3 & 2545.48 & 912.09 & $3,457.57$ & $2,079.24$ \\
\hline $23.00-24.00$ & 77.6 & 1241.87 & 133.27 & $1,375.14$ & 8.8 & 2894.22 & $1,176.27$ & $4,070.49$ & $2,695.35$ \\
\hline $00.00-01.00$ & 76.3 & 1232.08 & 135.53 & $1,367.61$ & 36.7 & 1965.66 & 281.80 & $2,247.46$ & 879.84 \\
\hline $01.00-02.00$ & 76.5 & 1228.71 & 135.19 & $1,363.90$ & 66.5 & 1936.38 & 155.64 & $2,092.01$ & 728.11 \\
\hline $02.00-03.00$ & 75.1 & 1225.79 & 137.71 & $1,363.50$ & 59.6 & 1936.20 & 173.46 & $2,109.65$ & 746.15 \\
\hline $03.00-04.00$ & 77.1 & 1232.12 & 134.18 & $1,366.30$ & 62.1 & 1874.23 & 166.59 & $2,040.82$ & 674.52 \\
\hline $04.00-05.00$ & 72.9 & 1224.64 & 141.97 & $1,366.61$ & 55.2 & 1868.02 & 187.43 & $2,055.45$ & 688.84 \\
\hline & & & & & & & & $\overline{\overline{\Delta \mathrm{UC}}}$ & $1,213.15$ \\
\hline
\end{tabular}


International Journal of Engineering Research and Technology. ISSN 0974-3154 Vol.13, No.4 (2020), pp. 725-733

(C) International Research Publication House. https://dx.doi.org/10.37624/IJERT/13.4.2020.725-733

Table 2. Comparison of maintenance costs postponed for 2, 6 and 12 months.

\begin{tabular}{|c|c|c|c|c|c|c|c|c|}
\hline \multirow{2}{*}{ Treatment Types } & \multicolumn{2}{|c|}{ Repair today } & \multicolumn{2}{|c|}{ Delay Cost for 2 months } & \multicolumn{2}{|c|}{ Delay Cost for 6 months } & \multicolumn{2}{|c|}{ Delay Cost for 12 months } \\
\hline & $\mathrm{AC}\left(10^{9}\right.$ IDR $)$ & UC (109 IDR) & $\mathrm{AC}\left(10^{9}\right.$ IDR $)$ & UC $\left(10^{9}\right.$ IDR $)$ & $\mathrm{AC}\left(10^{9}\right.$ IDR $)$ & UC (10 ${ }^{9}$ IDR $)$ & $\mathrm{AC}\left(10^{9} \mathrm{IDR}\right)$ & UC (10 ${ }^{9}$ IDR $)$ \\
\hline Preventive Maintenance & 0.252 & 0.029 & 0.254 & 0.029 & Do Nothing & 5.132 & Do Nothing & 10.406 \\
\hline Overlay $(50 \mathrm{~mm})$ & 0.630 & 0.029 & Do Nothing & 1.711 & 0.646 & 0.029 & Do Nothing & 10.406 \\
\hline Reconstruction & 14.070 & 0.029 & Do Nothing & 1.711 & Do Nothing & 5.132 & 14.785 & 0.030 \\
\hline
\end{tabular}

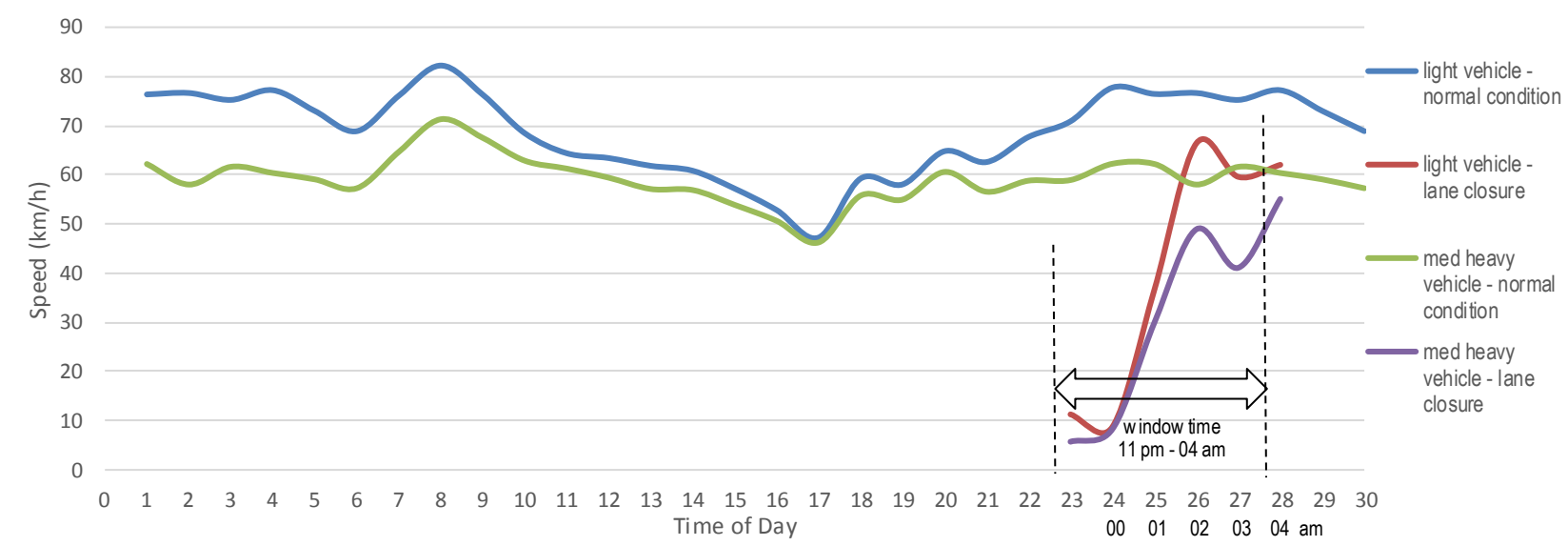

Figure 11. Speed average of a vehicle on a weekday day at JORRS



Figure 12. JORRS-customized traffic distribution patterns at weekday

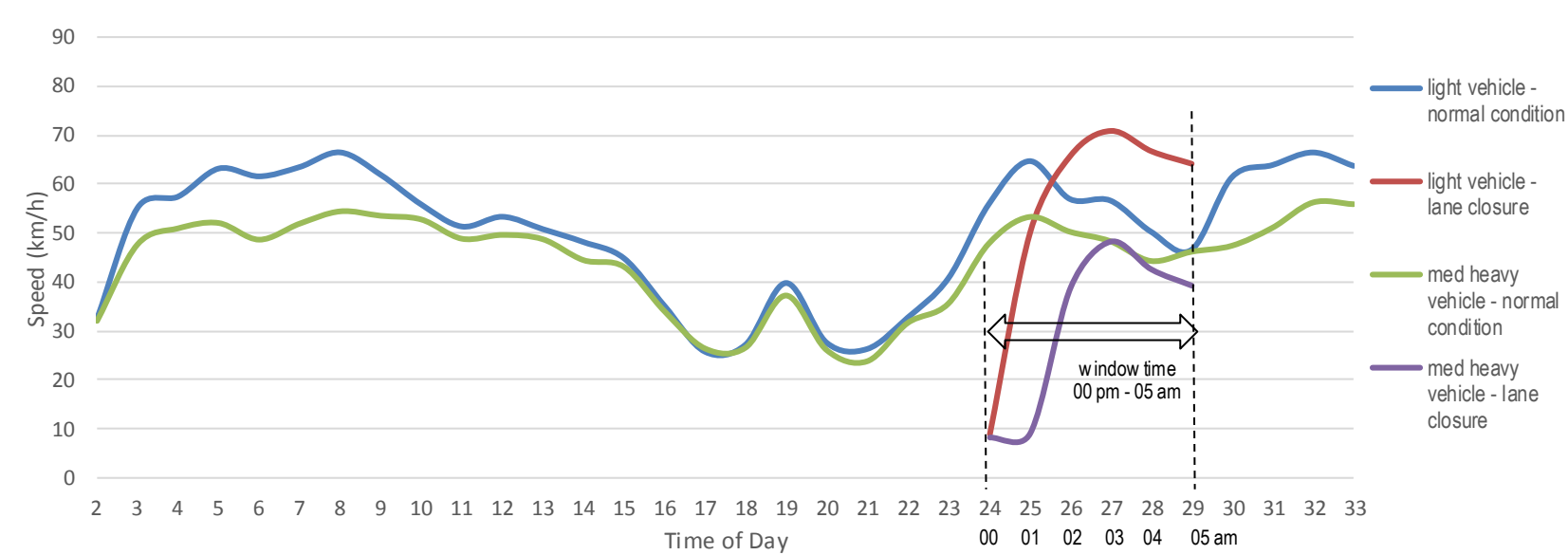

Figure 13. Speed average of a vehicle on a weekend day at JORRS 
From the characteristics of traffic on weekdays it looks solid at peak hours at $5 \mathrm{pm}$, where the average speed has decreased. Furthermore, when the lane / obstacle closure occurs the speed decreases below the average of $10 \mathrm{~km} /$ hour, this causes delays in the user arriving at their destination, these two conditions are illustrated in figure 11 and figure 12 . This condition is different from the characteristics at the weekend where traffic is relatively smoother with an average road capacity below $10 \%$ and average speed at $45 \mathrm{~km} / \mathrm{h}$, as illustrated in figure 13 and figure 14 .

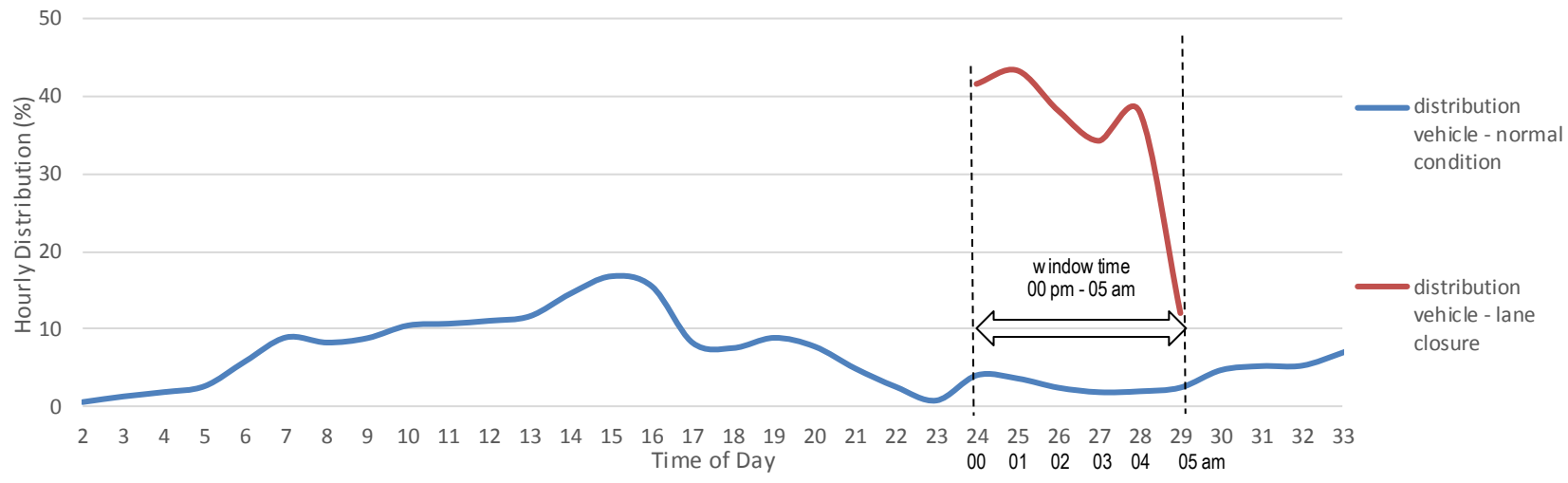

Figure 14. JORRS-customized traffic distribution patterns at weekend
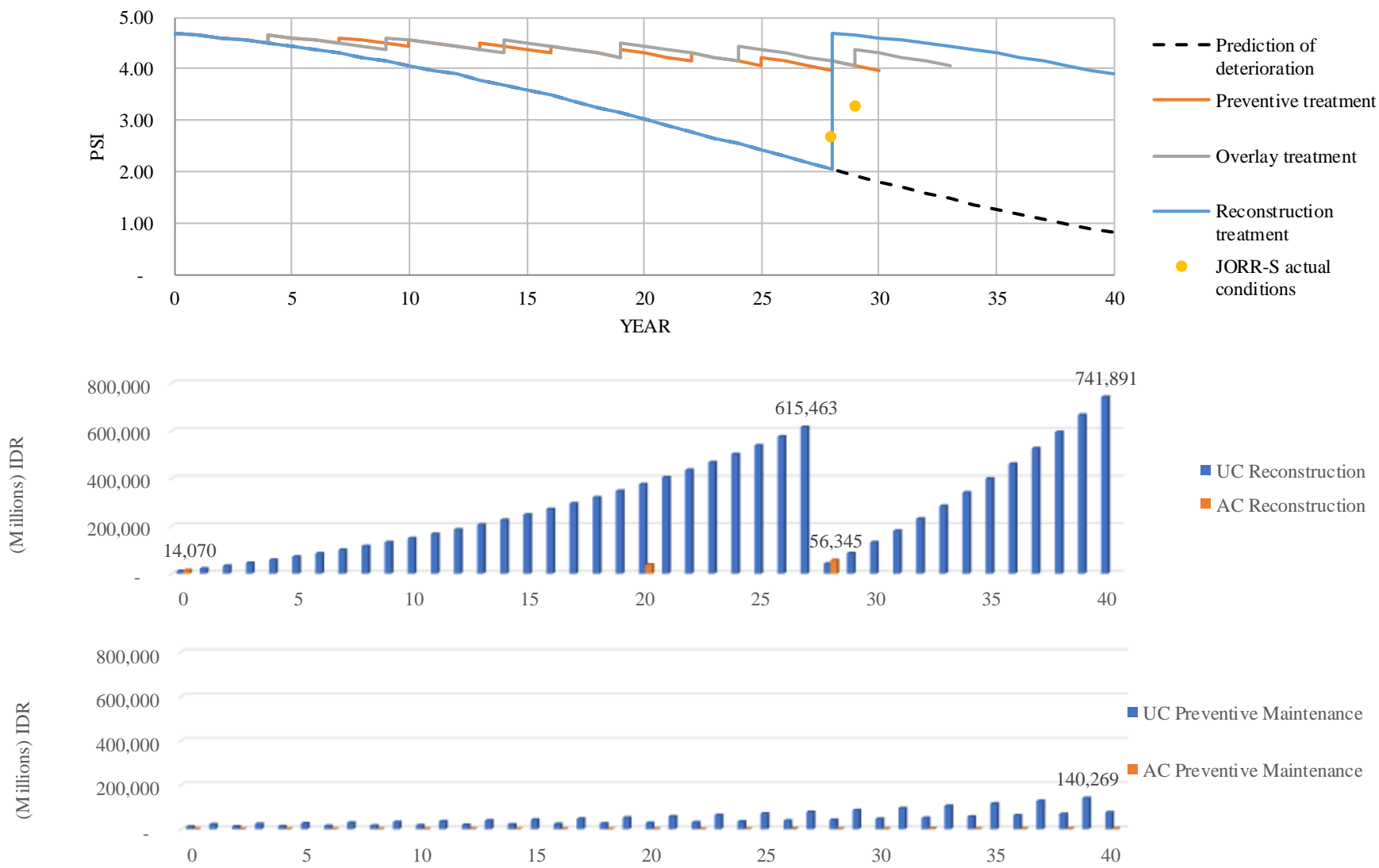

Figure 15 Pavement performance prediction, treatment, the future value calculation of reconstruction treatment compares with preventive treatment.

\section{RESULT AND DISCUSSION}

Based on the soft calculation, it can be seen that the road damage directly affects the decrease in speed, this causes an increase in vehicle operating costs and travel time. The impact for the agency isn't as much as it expected on current condition, next month, or next year repair doesn't add significant repair cost as illustrated in table 2 , the increase of maintenance cost for agency only around $5.08 \%$ for one-year delay maintenance.

Reconstruction treatment requires billion IDR 14.070/km/lane, if it is repaired next year, the agency costs can reach billion IDR $14.785 / \mathrm{km} /$ lane. This condition is different from road users who get additional travel costs due to delays in repairs. This can be seen from the cost of road users in the first year, billion 
IDR10.406 increased to billion IDR 167.070 for the following year due to a delay of repairs for a long period of one year.

Illustration of various types of improvements can be seen in Figure 15 which shows the agency cost chart compared to the cost of road users during the observation period, which is 40 years. An agency has conducted pavement management by considering the pavement performance conditions for a long time. Road user cost considerations have not been included in the calculation. In this study, the consideration of the cost of road users as one of the input variables that can be used by policy making, namely the component of vehicle operating costs due to a decrease in speed.

Overall, the preventive maintenance costs are relatively cheaper than overlay or even reconstruction maintenance costs, as illustrated in Table 3.

Table 3. Total costs for 20 years' life time

\begin{tabular}{|l|r|r|}
\hline \multirow{2}{*}{\multicolumn{1}{|c|}{ Treatment Types }} & \multicolumn{2}{c|}{ Total Cost (Future Worth) next 20 years } \\
\cline { 2 - 3 } & Agency (109 $\mathbf{~ I D R})$ & \multicolumn{1}{c|}{ User $\left(\mathbf{1 0}^{\mathbf{9}} \mathbf{~ I D R}\right)$} \\
\hline Preventive Maintenance & 6.43 & 544 \\
\hline Overlay (50 mm) & 4.32 & 1,352 \\
\hline Reconstruction & 51.97 & 3,456 \\
\hline
\end{tabular}

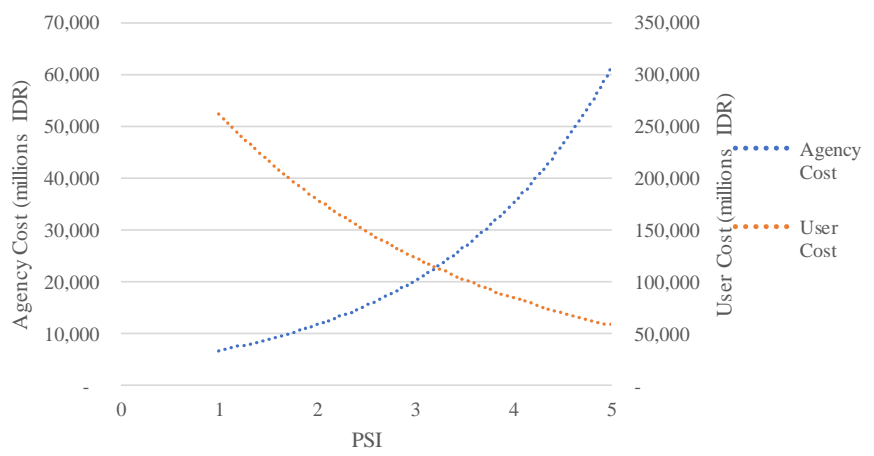

Figure 16. Comparison of agency costs and user costs based on pavement performance quality.

The actual pavement performance conditions in JORR-S are on average a PSI score $>3$, this is known from the results of the roughness test conducted in 2018 and 2019 after several preventive maintenance treatments were previously carried out. This proves that implementing preventive maintenance can extend the service life of the pavement.

The better the quality of the highway will cause minimal user costs; conversely, the worse the condition of the road will cause a considerable user cost. As explained in Figure 16, the relationship between user costs and agency costs with PSI is an illustration of the case study in JORR-S.

\section{CONCLUSION}

Pavement management plays an important role in creating sustainable pavement performance, including using LCCA in pavement management. Uncertain, ambiguous, and incomplete information is a problem in implementing LCCA, therefore, soft computing techniques are the right choice for solving problems. The advantage of using soft computing to develop
LCCA as has been done in this study is illustrated by the formulation and testing of fuzzy logic-based algorithms.

Delay in maintenance for a long time will cause increased costs for road users. Delaying road maintenance for a year as in this study will increase user costs to billion IDR10,406, while an increase in agency costs does not significantly.

Development of fuzzy-logic based LCCA by including road user variable costs, other variables such as accident rate, environmental impact can be carried out in further research.

\section{ACKNOWLEGMENT}

This research was funded by the Direktorat Riset dan Pengabdian Masyarakat Universitas Indonesia through the PIT9 Grant 2019, funded by contract no. NKB0076/UN2.R3.1/HKP.05.00/2019. The authors thank PT. HUTAMA KARYA (Persero), and The Transportation Laboratory of the Universitas Indonesia Civil Engineering Department

\section{REFERENCES}

[1] D. Iskandar, S. P. Hadiwardoyo, R. J. Sumabrata, and I. N. Fitriasari, "Road maintenance strategy with characteristic of drainage condition based on pavement performance," in AIP Conference Proceedings, 2018, vol. 1977, no. 1: AIP Publishing LLC, p. 040010.

[2] P. Kementerian, "Buku Informasi Statistik Pekerjaan Umum dan Perumahan Rakyat 2018," ed: Jakarta: Kementerian Pekerjaan Umum dan Perumahan Rakyat, 2018.

[3] S. Indonesia, "Land Transportation Statistics 2018," Statistics Indonesia, 2018.

[4] R. Justo-Silva and A. Ferreira, "Pavement maintenance considering traffic accident costs," International Journal of Pavement Research and Technology, vol. 12, no. 6, pp. 562-573, 2019, doi: 10.1007/s42947-0190067-3.

[5] T. Ding, L. Sun, and Z. Chen, "Optimal Strategy of Pavement Preventive Maintenance Considering Lifecycle Cost Analysis," Procedia - Social and Behavioral Sciences, vol. 96, pp. 1679-1685, 2013, doi: 10.1016/j.sbspro.2013.08.190.

[6] Y. Z. I. A. a. L. Wang, "Estimating Work Zone Road User Cost for Alternative Contracting Methods in Highway Construction Projects," Journal of Construction Engineering and Management, vol. 135, 7, 2009, doi: 10.1061/共 ASCE坖 CO.1943-7862.0000020。

[7] P. Babashamsi, N. I. Md Yusoff, H. Ceylan, N. G. Md Nor, and H. Salarzadeh Jenatabadi, "Evaluation of pavement life cycle cost analysis: Review and analysis," International Journal of Pavement Research and Technology, vol. 9, no. 4, pp. 241-254, 2016, doi: 10.1016/j.ijprt.2016.08.004.

[8] A. P. Singh, A. Sharma, R. Mishra, M. Wagle, and A. K. Sarkar, "Pavement condition assessment using soft computing techniques," International Journal of Pavement Research and Technology, vol. 11, no. 6, pp. 564-581, 2018, doi: 10.1016/j.ijprt.2017.12.006. 
International Journal of Engineering Research and Technology. ISSN 0974-3154 Vol.13, No.4 (2020), pp. 725-733

(C) International Research Publication House. https://dx.doi.org/10.37624/IJERT/13.4.2020.725-733

[9] T. R. Panda and A. K. Swamy, "An improved artificial bee colony algorithm for pavement resurfacing problem," International Journal of Pavement Research and Technology, vol. 11, no. 5, pp. 509-516, 2018, doi: 10.1016/j.ijprt.2018.04.001.

[10] D. S. S. J. Yogesh U. Shah, Dr. Devesh Tiwari and Dr.M.K. Jain, "Soft Computing Applications for Urban Pavement Maintenance Management System," in International Conference on Advances in Architecture and Civil Engineering (AARCV 2012), 2012, vol. 1, pp. 542-547.

[11] C. Chen, "Soft computing-based life-cycle cost analysis tools for transportation infrastructure management," Virginia Tech, 2007.

[12] L. A. Zadeh, "The roles of fuzzy logic and soft computing in the conception, design and deployment of intelligent systems," in Software Agents and Soft Computing Towards Enhancing Machine Intelligence: Springer, 1997, pp. 181-190.

[13] S. Terzi, "Modeling for pavement roughness using the ANFIS approach," Advances in Engineering Software, vol. 57, pp. 59-64, 2013, doi: 10.1016/j.advengsoft.2012.11.013.

[14] G. Daniels, W. R. Stockton, and R. Hundley, "Estimating road user costs associated with highway construction projects: simplified method," Transportation research record, vol. 1732, no. 1, pp. 7079, 2000.

[15] S. Islam and W. G. Buttlar, "Effect of pavement roughness on user costs," Transportation Research Record, vol. 2285, no. 1, pp. 47-55, 2012.
[16] D. Kalimanto and S. Hadiwardoyo, "Impact of road rehabilitation zone on travel time to road user cost," in IOP Conference Series: Materials Science and Engineering, 2019, vol. 673, no. 1: IOP Publishing, p. 012114.

[17] B. M. B. d. Santos, L. s. G. de Picado-Santos, and V. M. P. Cavaleiro, "Simplified model of road-user costs for Portuguese highways," Transportation research record, vol. 2225, no. 1, pp. 3-10, 2011.

[18] B. Santos and L. s. Picado-Santos, "Impact assessment of road work zones in operating conditions, safety and user costs," in World Conference on Pavement and Asset Management, Milan, Italy, 2017.

[19] N. R. Council, Highway capacity manual 2010. TRB, 2010.

[20] C. Chen, G. Flintsch, and I. Al-Qadi, "Fuzzy logicbased life-cycle costs analysis model for pavement and asset management," in 6th International Conference on Managing Pavements, 2004: Citeseer, pp. 19-24.

[21] J. Walls and M. R. Smith, "Life-cycle cost analysis in pavement design: Interim technical bulletin," United States. Federal Highway Administration, 1998.

[22] P. P. B. O. Kendaraan, "Pd T-15-2005-B Badan Litbang PU Departemen Pekerjaan Umum," ed: Jakarta, 2005. 